\title{
Análise dos sistemas de alocação de órgãos para transplantes do aparelho digestivo no Brasil
}

Wellington Andraus ${ }^{1}$, Luciana Haddad², Vinícius Rocha-Santos ${ }^{3}$, Luiz Augusto Carneiro D'Albuquerque ${ }^{4}$

\section{Introdução}

\author{
A
} organização dos sistemas de alocação de órgãos para transplantes passou por várias fases no Brasil desde o início dos transplantes de órgãos neste país. Inicialmente as equipes transplantadoras realizavam a procura de órgãos para os seus próprios receptores, com busca ativa em unidades de terapia intensiva, e alocavam os órgãos em sua lista de espera seguindo seus próprios critérios. Na década de 80, alguns estados como o Rio de Janeiro, São Paulo e Rio Grande do Sul criaram as primeiras organizações na tentativa de regulamentar a notificação e alocação de órgãos para transplante. Um exemplo foi a criação do SPIT, São Paulo Interior Transplantes, em 1986. Passou-se a distribuir os órgãos por um rodízio de equipes transplantadoras cadastradas, contudo as equipes continuavam selecionando e alocando os órgãos para os seus receptores com critérios próprios, que durou até 1997. 1,2,3

Apesar de em 1968 ter sido proposta uma lei sobre o consentimento informado na doação, esta lei não foi regulamentada. Em Julho de 1990 foi criada na Secretaria do Estado de São Paulo o Banco de Órgãos e Tecidos e Substâncias Humanas, e também foram criadas normas de regulamentação para a retirada e alocação de órgãos e tecidos. E só em 1992, com a lei 8.489, é que foi regulamentado o consentimento informado para a doação e tecidos. E em julho de 1993 foi incorporado o conceito de morte encefálica. ${ }^{1,2,3}$

A lei 9.434 de 04 de Fevereiro de 1997 teve um papel muito importante para o transplante de órgãos no Brasil, que dispõe sobre a remoção de órgãos, tecidos e partes do corpo humano para fins de transplante. A seguir, o Decreto 2.268 de 30 de junho de 1997 criou o Sistema Nacional de Transplantes (SNT), implantou as Centrais de Notificação e Distribuição de Órgãos (CNCDOs). Houve a criação do Cadastro Técnico Único (CTU), que define uma lista única para cada região sobre a jurisdição das CNCDOs. Alterase assim a alocação de órgãos e tecidos para cronologia, priorizando o maior tempo de espera em lista para a classificação dos receptores compatíveis buscando uma maior equidade e justiça. O SNT é o órgão federal que vai legislar sobre os transplantes em todo o Brasil. ${ }^{1,2,3}$

Esta resolução de 1997 definiu as atribuições de todos os integrantes do sistema que envolve todos os processos do transplante, os critérios de alocação
1. Livre Docente pelo Departamento de Gastroenterologia HCFMUSP. Coordenador de Ensino do Serviço de Transplante de Órgãos do Aparelho Digestivo - HCFMUSP

2. Pós-Doutoranda pelo Departamento de Gastroenterologia HCFMUSP. Médica Assistente do Serviço de Transplante de Órgãos do Aparelho Digestivo - HCFMUSP

3. Doutor pelo Departamento de Gastroenterologia - HCFMUSP. Chefe do Grupo de Transplante de Pâncreas do Serviço de Transplante de Órgãos do Aparelho Digestivo - HCFMUSP

4. Prof Titular do Serviço de Transplante de Órgãos do Aparelho Digestivo - HCFMUSP
Artigo recebido em 26/08/2013 Aprovado para publicação em 20/09/2013 
de órgãos, e constitui as Comissões Técnico-Científicas. Esta lei alterou também, na doação, o consentimento informado para presumido, que entrou em vigor em janeiro de 1998. Não houve respaldo da sociedade para esta forma de doação e houve até uma diminuição no número de doadores após sua implementação. Em 23 de março de 2001, a lei 10.211, retorna então a forma de manifestação à doação para o consentimento informado, sendo necessária a autorização familiar para a sua realização. ${ }^{1,2,3}$

Esta lei federal também permitiu a divisão de Estados da Federação em mais de uma lista de espera, de acordo com critérios populacionais e logísticos de captação e alocação de órgãos. Um exemplo é o Estado de São Paulo que foi dividido em duas regionais: Regional 1 (São Paulo capital, Grande São Paulo, Vale do Ribeira e Litoral) com 20,9 milhões de pessoas, e Regional 2 (todo interior do Estado) com 18,5 milhões de pessoas. As regionais são subdivididas em OPOs ( Organização para Procura de Órgãos) com suas respectivas áreas de abrangência. Tomando como exemplo a cidade de São Paulo, esta possui quatro OPOs, localizadas no Hospital das Clínicas da Universidade de São Paulo (HCFMUSP), no Hospital Santa Casa da Misericórdia de São Paulo, Hospital São Paulo da Escola Paulista de Medicina (EPM), e no Hospital Dante Pazzanese. 1,2,3

A resolução do Conselho Federal de Medicina 1.480/97, de 08 de agosto de 1997, estabelece o conceito de morte encefálica como sendo a parada total e irreversível da atividade do tronco e dos hemisférios cerebrais, e orienta que a hora do óbito é aquela registrada no Termo de Declaração de Morte Encefálica, após a realização do exame complementar que confirma este diagnóstico. Cada equipe de retirada de órgãos deve checar esta Declaração antes do início do processo de captação. ${ }^{1,2,3}$

Em 2001 a portaria 905/2000 cria as Comissões Intra-hospitalares de Doação de Órgãos e Tecidos para Transplantes (CIHDOTTs), uma importante medida, baseada no modelo espanhol, que visa aumentar o número de doadores efetivos no país. E a portaria de 23 de março de 2005 determina a obrigatoriedade destas comissões em todos os hospitais com mais de 80 leitos. Com estas medidas o Brasil tem realmente melhorado o número de doadores efetivos no país. Com estas medidas o Brasil tem realmente melhorado o número de doadores efetivos por milhão de habitantes por ano. Há alguns anos encontrávamos próximos de 7 em doadores por milhão de habitantes e atualmente estamos com 10,7, em aumento importante, contudo ainda não satisfatório, pois ainda existe uma grande escassez de órgãos no país. .,2,3 $^{1,2}$

A portaria 2.600 de 21 de outubro de 2009 aprova o Regulamento Técnico do Sistema Nacional de Transplantes e esta regulamentação é a que encontra-se em vigência atualmente. ${ }^{1,2,3}$

O Brasil possui atualmente o maior programa público de transplantes do mundo. O SUS (Sistema Único de Saúde) custeou entre 2002 e 200512.352 transplantes de órgãos e tecidos. Contudo apesar dos números absolutos serem tão importantes, devido ser o Brasil um país populoso e de dimensões continentais, os números relativos estão ainda aquém do necessário para a grande maioria dos órgãos que tem indicações de transplante. No caso do fígado como exemplo, a necessidade estimada é de 25 por milhões de habitantes por ano, e realizamos apenas $1 / 3$ desta necessidade, aproximadamente 8 , segundo dados da ABTO. E com certeza a alocação de órgãos torna-se muito mais difícil e complexa na vigência de uma grande escassez de órgãos. ${ }^{4,5}$

\section{Processo de doação e alocação de órgãos}

O processo de doação e alocação de órgãos deve seguir uma ordem, sob a supervisão das CNCDOs, no intuito de que as equipes transplantadoras não se envolvam no processo de doação e evitem assim potenciais conflitos de interesse.

Após a detecção de um potencial doador pelo médico que o assiste em um determinado hospital, o mesmo deve notificar à CNCDO ou OPO (Organização para Procura de Órgãos) de referência, esta notificação é compulsória. Após a notificação este potencial doador deve ser mantido em boas condições, com estabilidade hemodinâmica, tratamento de infecções, correção de distúrbios hidroeletrolíticos, etc. A CNDO ou OPO faz o diagnóstico de morte encefálica, respeitando as resoluções do Conselho Federal de Medicina, realiza-se avaliação clínica e laboratorial verificando se não existem contraindicações para a doação de órgãos. É realizada a abordagem familiar por pessoal treinado para estas situações, e obtém-se o consentimento familiar. A morte encefálica é então documentada e inicia-se a logística para a remoção de órgãos e tecidos. As Centrais de Transplantes irão alocar os órgãos de acordo com a ordem da lista em seu cadastro técnico. ${ }^{2,3,6}$ 
Somente neste momento as equipes transplantadoras são notificadas, seguindo a ordem da lista espera dos respectivos receptores cadastrados nas centrais. Cada órgão irá obedecer o seu critério específico de alocação, sendo a maioria por cronologia.

Um dos maiores problemas da quantidade reduzida de doadores de múltiplos órgãos no Brasil é a baixa notificação. A taxa estimada de morte encefálica por milhão por ano é de 50 a 60 . Considerando a taxa de morte encefálica intra-hospitalar, esta está em torno de 1 a $4 \%$ e em terapia intensiva de 10 a $15 \%$. Estima-se que cerca de dois terços das mortes encefálicas não são notificadas no Brasil. ${ }^{5,7}$

\section{Ficha complementar/critérios de exclusão}

Para a alocação de órgãos as Centrais de Transplantes utilizam também uma ficha complementar. Esta ficha, as equipes transplantadoras preenchem para cada receptor, com a sua anuência ou de um responsável, com dados que buscam para o respectivo doador. A ficha tem o objetivo de promover a compatibilidade mínima com seu respectivo receptor, como por exemplo o peso e altura, o IMC, dados laboratoriais, idade, entre outros. Assim facilita-se a alocação dos órgãos por parte das Centrais de Transplante, pois não há a necessidade de abordagem de equipes que negariam com certeza o órgão, com atraso do processo de doação/captação, e também garante-se um mínimo de compatibilidade entre doador e receptor, ou a aceitação de critérios expandidos quando a equipe e o receptor estão de acordo. ${ }^{2,3}$

Os critérios absolutos de exclusão de doador de órgãos são: soropositividade para HIV; soropositividade para HTLV I e II; tuberculose em atividade; neoplasias (exceto tumores primários do Sistema Nervoso Central e carcinoma in situ de útero e pele); sepse refratária; infecções virais e/ou fúngicas graves na presença de imunossupressão, exceto as hepatites B e C. ${ }^{3,6}$

\section{Alocação de fígado}

O enxerto de fígado seguiu uma alocação cronológica regulamentada em 1997 até sua mudança para critério de gravidade seguindo o escore MELD (Model for End-stage Liver Disease) que é um modelo matemático para doenças hepáticas em fase avançada que mostrou-se ser um bom preditor de mortalidade a curto prazo.
A fórmula do MELD é uma conta logarítmica que leva em consideração os valores de creatinina sérica $(\mathrm{Cr})$, da bilirrubina total sérica (BT) e do INR ( razão internacional para o tempo de protrombina) e cuja fórmula é a seguinte : $(0,957 \mathrm{x} \log \mathrm{Cr}+0,378 \mathrm{x}$ $\log \mathrm{BT}+1,12 \times \log \mathrm{INR}+0,643) \times 10$. Foi inicialmente descrito em 2000 por Malinchoc et al, que desenvolveram a fórmula como preditor de mortalidade a curto prazo para pacientes que seriam submetidos a TIPS ( shunt portossistêmico intra-hepático). Esta fórmula mostrou-se ser um ótimo preditor de mortalidade para pacientes cirróticos de maneira geral, e quando os valores se aproximam-se de 40, a mortalidade em 3 meses é de aproximadamente 100\%. Por este motivo, em fevereiro de 2002, adotou-se nos EUA como modelo de alocação de enxertos hepáticos por gravidade. No Brasil esta mudança ocorreu apenas em Julho de 2006, após a portaria 1.160 de maio de 2006 que implanta o critério de gravidade de estado clínico do paciente para a alocação. ${ }^{3,8}$

Para efeito de cálculo, na fórmula, coloca-se o valor de creatinina até um máximo de 4 . Os pacientes que são dializados com frequência igual ou superior a 2 vezes por semana recebem um valor fixo de $\mathrm{Cr}$ de 4 para o cálculo do escore MELD. Os pacientes que estiverem em uso de dicumarínico tem o valor de INR fixado em 2,5 também para efeito do cálculo do MELD. ${ }^{2,3}$

Os pacientes com idade entre 12 e 18 anos tem o valor do MELD multiplicado por 2 para efeito de alocação. Já os pacientes menores de 12 anos existe uma fórmula um pouco diferente, o PELD ( Pediatric End-stage Liver Disease), que leva também em conta a BT e o INR, mas ao invés da Cr, utiliza-se o valor da albumina sérica na fórmula e também leva-se em consideração a idade da criança e o déficit de crescimento. O valor do PELD é então multiplicado por 3 para efeito de alocação. ${ }^{2,3}$

Cabe ressaltar o tempo de validade da pontuação destes escores e dos respectivos exames laboratoriais. No caso do MELD, quando a pontuação é até 10 , este tem validade por 12 meses e os exames para efeito do cálculo devem ter sido colhidos com antecedência de até 30 dias. Na pontuação entre 11 e 18 a validade é de 3 meses e os exames podem anteceder em no máximo 14 dias. Entre 19 e 25 pontos a validade é de 1 mês e exames dos últimos sete dias. Quando o MELD é maior que 25, este vale por 7 dias e os exames devem ser das últimas 48 horas. Para o PELD da mesma forma existem faixas de validade do escore dos exames utilizados para o cálculo., 
A alocação dos enxertos de fígado obedece a regionalização, a compatibilidade $\mathrm{ABO}$ e o escore MELD. Para o desempate utiliza-se o tempo de inscrição na lista de espera.

Existem alguns critérios de priorização, e a priorização não obedece a regionalização. Dentre eles: hepatite fulminante, disfunção primária do enxerto até o sétimo dia de pós operatório, e paciente anepático por trauma. A priorização por insuficiência hepática aguda (hepatite fulminante) obedece alguns critérios pré-definidos, sendo que utilizamos o inglês, do King`s College, ou o francês, de Clichy. ${ }^{2,3}$

\section{1- Critérios do King`s College para hepatite fulminante (A e $B$ ):}

A- Com ingestão de acetaminofen:

- $\mathrm{pH}$ sérico menor que 7,3;

- Tempo de protrombina maior que $100 \mathrm{seg}$ ou INR maior que 6,5;

- Encefalopatia grau III ou IV.

B- Sem ingestão acetaminofen:

B1- Tempo de protrombina maior que $100 \mathrm{seg}$ ou INR maior que 6,5 independentemente do grau de encefalopatia;

B2- Ou três dos seguintes critérios:

- Idade menor que 10 anos ou maior que 40 anos;

- Etiologia por causas que não o Vírus A ou B;

- Icterícia de aparecimento com intervalo maior do que 7 dias após o início da encefalopatia;

- Tempo de protrombina maior que $50 \mathrm{seg}$ ou INR maior que 3,5;

- Bilirrubina total maior do que 17,5.

\section{2- Critérios de Clichy para hepatite fulmi- nante:}

- Encefalopatia grau III ou IV;

- Fator V menor que 30\% em pacientes com mais de 30 anos;

- Fator V menor que $20 \%$ em pacientes com menos de 30 anos.

Além das priorizações existem também situações nas quais o MELD não se eleva a estes pacientes são graves e tem alta mortalidade. Estes pacientes não contemplados pelo escore MELD recebem pontuações especiais para que possam também ser transplantados. As situações especiais são:

-Adenomatose múltipla;

- Carinoma fibrolamelar;
- Doenças metabólicas com a fibrose cística, tirosinemia, glicogenose tipo I;

- Hemangioendotelioma;

- Hemangioma gigante irressecável ou doença policística que provoque síndrome compartimental;

- Hepatoblastoma;

- Carcinoma hepatocelular;

- Insuficiência hepática pós doação de fígado (calculado o valor do MELD);

- Insuficiência hepática pós doação de órgão sólido;

- Poliamiloidose familiar (PAF);

- Síndrome hepatopulmonar;

- Trombose de artéria até o $15^{\circ}$ dia de pós operatório;

- Tumor neuroendócrino metastático irressecável e restrito ao fígado ( foco primário ressecado );

- Prurido intratável;

- Encefalopatia hepática;

- Ascite refratária.

Os pacientes em situação especial recebem uma pontuação equivalente ao escore MELD de 20 pontos inicialmente, que em 3 meses passa para 24 pontos e em 6 meses para 29 pontos. A intenção é de que estes pacientes sejam transplantados com intervalo próximo a seis meses após a sua indicação, contudo este período vai depender do número de doadores e da demanda por transplantes na respectiva regional, que vai interferir diretamente no valor do MELD que os pacientes são transplantados para um determinado tipo sanguíneo. . $^{2,3,5}$

Devemos destacar o carcinoma hepatocelular (CHC) dentre as etiologias que recebem situação especial, pelo motivo de sua alta frequência em pacientes cirróticos e em alcançar em muitos serviços até mais de $1 / 4$ das indicações do total de transplantes hepáticos realizados. Na legislação brasileira o carcinoma hepatocelular deve obedecer os critérios de Milão para poder entrar ou permanecer em lista de espera e receber pontuação especial. ${ }^{2,3,5}$

Os critérios de Milão foram publicados por Vincenzo Mazzaferro em 1996 e determinam que para o transplante de fígado em receptores que tem $\mathrm{CHC}$, este deve ter:

- nódulo único de até $5 \mathrm{~cm}$ ou até 3 nódulos de até $3 \mathrm{~cm}$

- ausência de invasão vascular macroscópica

- ausência de lesões extra-hepáticas 
Com estes critérios a sobrevida do transplantado de fígado por CHC alcançou resultados semelhantes àqueles transplantados devido a outra etiologias. Para o diagnóstico do CHC a legislação brasileira adotou os critérios de Barcelona, que define em exame de tomografia ou ressonância um nódulo maior ou igual a $2 \mathrm{~cm}$, com realce vascular na fase arterial e lavagem ("washout") na fase venosa. Casos de CHC que ultrapassem os critérios de Milão podem ser colocados em lista e receber pontuação para situação especial (Downstaging). Existe uma grande discussão a nível mundial sobre a expansão dos critérios de indicação de transplantes em casos de $\mathrm{CHC}$, com várias propostas com critérios acima dos preconizados por Mazzaferro, alcançado sobrevida aceitável, como os critérios de São Francisco, os Critérios da Coréia do Sul do ASAN Medical Center, entre outros. Por outro lado, no Brasil, devido ainda a grandeza escassez de órgãos não houve ainda espaço para discussão da ampliação dos critérios atualmente adotados. ${ }^{2,3,5}$

É importante mencionarmos os casos de transplantes intervivos, nos quais não existe a necessidade de espera em fila ou de alocação, contudo os receptores podem ou não estar inscritos na lista de espera de doador falecido. Caso o paciente esteja inscrito em lista de espera para doador falecido e necessite de um retransplante que tenha critérios de priorização, ele poderá receber um fígado da lista de espera de doador falecido. Caso contrários, se ele não estiver inscrito, por exemplo caso apresente um CHC acima dos critérios de Milão, este não poderá ser retransplantado utilizando um órgão de doador falecido. . $^{2,3}$,

\section{Alocação de pâncreas}

O transplante de pâncreas é realizado na grande maioria das vezes em concomitância com o transplante renal. Nesta modalidade, a alocação para o transplante de pâncreas/rim segue uma ordem cronológica, separados pelos respectivos grupos sanguíneos. A única indicação de prioridade para o transplante de pâncreas/rim é a impossibilidade de acesso venoso ou peritoneal para realização da diálise. ${ }^{2,3,5}$

Normalmente, o tempo de espera em lista para o transplante de pâncreas/ rim é menor que o transplante de rim isolado. Contudo esta modalidade tem critérios mais restritivos para o doador. A idade deve estar entre 10 a 45 anos, o peso entre 30 e $90 \mathrm{Kg}$, e deve haver a ausência de Diabetes Mellitus no pró- prio doador ou em parentes de primeiro grau. Doadores com índice de massa corpórea acima de 30 são descartados para esta modalidade de transplante. Para os pacientes que são indicados para transplante duplo ( pâncreas/rim) e já estavam na lista de espera para transplante renal, conta a data inicial de entrada em lista de espera do transplante renal. Além disso, como no transplante renal, o pâncreas também utiliza o antígeno de histocompatibilidade leucocitário ( HLA), além da compatibilidade sanguínea $\mathrm{ABO}$, para verificar uma maior compatibilidade entre doador e receptor, e após então o órgão é alocado por cronologia. $\mathrm{O}$ teste de "HLA" é realizado por uma prova cruzada ("crossmatch") entre amostras de sangue e linfonodos do doador e sangue do receptor. Para isto faz-se necessário que o receptor mantenha uma amostra de sangue estocada no laboratório de referência., 2,3,5

Uma das críticas é a demora na realização deste exame o que aumenta o tempo de isquemia fria no transplante do órgão. Atualmente está sendo implantado o exame de "crossmatch" virtual, que irá diminuir bastante o tempo de realização do exame, favorecendo as equipes de transplante de pâncreas.

No caso de transplantes de pâncreas isolado segue-se também a ordem cronológica, a compatibilidade $\mathrm{ABO}$ e HLA, contudo o doador é um pouco menos restritivo, excluindo doadores com idades menores que 5 anos e maiores que 51 anos. Além disso não há regionalização para o transplante de pâncreas isolado. ${ }^{2,3,5}$

\section{Alocação de intestino e multiviceral}

A alocação do intestino isolado segue também uma ordem cronológica.

No caso de transplante multivisceral, que inclui o fígado, a lista deve seguir as regras de alocação hepática, utilizando o escore MELD. Ainda não existe uma legislação totalmente definida, e como estes pacientes são muito graves, o número de transplantes é muito pequeno, discute-se uma priorização através de uma pontuação especial no escore MELD.

\section{Considerações finais}

O sistema de alocação de órgãos para transplante no Brasil atual talvez não seja perfeito, mas com certeza é muito mais justo do que já foi no passado. 
Existe a necessidade de reavaliações constantes nos critérios de alocação para transplante, para aproximarmos cada vez mais da justiça e da equidade.

O aumento do número de doadores efetivos em todo o Brasil, sejam eles falecidos ou doadores vivos, irá facilitar o sistema de alocação, diminuindo a lista de espera e melhorando a sobrevida global de nossos pacientes, não só pós transplante mas desde o momento de sua indicação.

\section{Referências}

1- Ministério da Saúde - Sistema Nacional de Transplantes www.saude.gov.br/transplantes (acesso - julho de 2013)

2- Conselho Nacional de Saúde - www.conselho.saude.gov.br (acesso - julho de 2013)

3- Secretaria de Saúde do Estado de São Paulo www.saude.sp.gov.br (acesso - julho de 2013)

4- DATASUS - www.datasus.gov.br (acesso - julho de 2013)

5- Associação Brasileira de Transplantes de Órgãos www.abto.org.br (acesso - julho de 2013)

6- Diretrizes básicas para captação de órgãos e tecidos da ABTO - Companygraf Produções Gráficas e Editora - 2009

7- Aliança Brasileira pela Doação de Órgãos e Tecidos www.adote.org.br (acesso - julho de 2013)

8- Malinchoc M, Kamath PS, Gordon FD, Peine CJ, Rank J, ter Borg PC. A model to predict poor survival in patients undergoing transjugular intrahepatic portosystemic shunts. Hepatology. 2000;31:864-71. 